\title{
Fracturing surgical valves to improve hemodynamics in transcatheter aortic valve-in-valve replacement: Insanity or ingenuity?
}

Vinayak Bapat, MBBS, MS, DNB, FCRS.Ed, FRCS.CTh, ${ }^{a}$ and Gilbert H. L. Tang, MD, MSc, MBA ${ }^{b}$

From the ${ }^{\mathrm{a}}$ Division of Cardiac Surgery, Columbia University Medical Center, New York, NY; and ${ }^{\mathrm{b}}$ Department of Cardiovascular Surgery, Mount Sinai Health System, New York, NY.

Received for publication Oct 2, 2017; revisions received Jan 13, 2019; accepted for publication Jan 15, 2019; available ahead of print April 1, 2019

Address for reprints: Vinayak Bapat, MBBS, MS, DNB, FCRS.Ed, FRCS.CTh, Division of Cardiac Surgery, Columbia University Medical Center, 177 Fort Washington Ave, Floor MHB 7-435, New York, NY 10032 (E-mail: vnbapat@yahoo.com).

J Thorac Cardiovasc Surg 2019;158:72-5

$0022-5223 / \$ 36.00$

Copyright $(C) 2019$ by The American Association for Thoracic Surgery

https://doi.org/10.1016/j.jtcvs.2019.01.132

Use of bioprosthetic surgical heart valves (SHVs) is on the rise, especially in younger patients. ${ }^{1}$ A large number of these patients will likely require at least 1 reintervention during their lifetime, and valve-in-valve (VIV) has emerged as a novel option whereby a transcatheter heart valve (THV) is implanted within a failing SHV. VIV has recently been approved in patients deemed high or extreme risk for reoperative surgical aortic valve replacement (SAVR). ${ }^{2-4}$ Transcatheter VIV replacement in failing mitral, tricuspid, and pulmonic bioprostheses has also shown favorable outcomes in high-risk patients. ${ }^{5-9}$ Potential advantages of VIV therapy over a high-risk reoperation include a shorter and simpler procedure, lower mortality, reduced risk of morbidities, including bleeding and renal injury, shorter length of stay, and more rapid recovery. ${ }^{2-9}$ In 1962, Dwight Harken ${ }^{10}$ defined " 10 Commandments" to describe a perfect valve substitute, but current mechanical and bioprosthetic SHVs fall short of those features. Mechanical valves can be durable but require lifelong anticoagulation, whereas bioprosthetic valves may not need anticoagulation and are noise free but will definitely degenerate. ${ }^{10}$ In a way, VIV can take us a step closer to achieving these $10 \mathrm{Com}$ mandments if we can demonstrate the safety and efficacy of this approach, and in addition modify design of the bioprosthetic SHV to accommodate VIV, that is, THV proof designs.

However, VIV therapy in degenerated SHVs has several potential pitfalls, which need to be overcome and its effectiveness proven if the therapy were to be offered to lowerrisk patients. These are the risks of malposition, coronary obstruction, leaflet thickening/thrombosis, and "Russian doll" effect.

\section{TRANSCATHETER HEART VALVE MALPOSITION}

Malposition is a well-recognized complication whereby THV is placed too low or too high, resulting in suboptimal hemodynamics or embolization. Other than operator

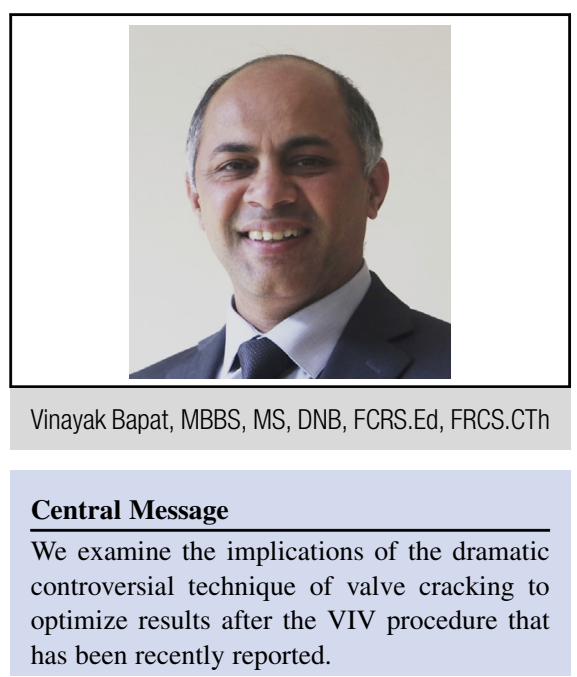

experience, the main cause is suboptimal fluoroscopic landmarks in certain SHV. Because the VIV procedure is performed under fluoroscopy, an SHV with no or poor fluoroscopic landmarks poses a challenge in optimal THV positioning. This is confirmed by the fact that stentless valves and Mosaic bioprostheses (Medtronic Inc, Galway, Ireland) have the highest incidence of malposition. ${ }^{4}$

\section{CORONARY OBSTRUCTION}

Coronary obstruction is a life-threatening complication after the VIV procedure. During a VIV procedure, the coronary arteries are at risk of occlusion as the stent posts and leaflets of the SHV are pushed outward toward the coronary ostia. Risk of coronary obstruction after a VIV procedure is higher than after transcatheter aortic valve replacement (TAVR) in a native aortic valve, with an incidence of $2.5 \%$ to $3.5 \%$ compared with less than $1 \% .^{11,12}$ It is a combination of small aortic root, relationship of the coronary ostia to the SHV, and certain valve designs (ie, SHV with leaflets mounted outside the stent frame) that increase coronary obstruction risk. $^{11}$ Multidetector computed tomography analysis can help predict the risk of coronary occlusion in VIV TAVR. ${ }^{12}$ If reoperation is not deemed feasible, VIV can be performed with coronary protection and immediate PCI if coronary flow becomes jeopardized. A novel technique named "Bioprosthetic Aortic Scallop Intentional Laceration to prevent Iatrogenic Coronary Artery obstruction" (BASILICA) may also reduce the risk of coronary obstruction during VIV 
TAVR, especially if the aortic root to coronary anatomy is not favorable for percutaneous coronary intervention. ${ }^{13}$

\section{LEAFLET THICKENING AND THROMBOSIS}

The third issue is related to the extent of THV oversizing relative to the implanted bioprosthesis, especially in small SHVs. VIV is susceptible to leaflet thickening or thrombosis, especially in smaller-sized SHVs. ${ }^{14,15}$ Several mechanisms may be responsible, including insufficient eddy currents to achieve optimal leaflet closing, increased blood stasis on THV leaflets and adjacent frame inside the surgical valve, and under-expansion of the THV inside the small SHV, leading to crowding and a pinwheel effect on the THV leaflets. ${ }^{14-16}$ Optimal sizing and anticoagulation, when necessary, are potential strategies to prevent this complication.

\section{"RUSSIAN DOLL" EFFECT}

Finally, VIV can result in further reduction in the effective orifice area and thus persistent residual gradients, that is, the "Russian doll" effect. ${ }^{4,17-19}$ This is especially true in an SHV with manufacturer label size $21 \mathrm{~mm}$ or less or a stenotic SHV. ${ }^{4}$ Residual gradients have been shown to result in patient-prosthesis mismatch (PPM) and affect survival. ${ }^{4}$

Although some factors to optimize the hemodynamics can be controlled by the operator, such as the type of THV used and ensuring optimal depth of implantation, ${ }^{17-19}$ it is clear that there are certain limitations set by the SHV in situ, especially when moderate to severe PPM already exists in the SHV. Each SHV is unique in its construct but has 3 components: sewing ring, stent frame, and leaflets. ${ }^{20}$ The sewing ring or the inflow of the SHV tends to be the narrowest portion of the SHV and is referred to as the "neoannulus." ${ }^{21}$ Stent posts and leaflets are deflected outward, but the inflow dimensions at the level of "neo-annulus" remain constant; thus, the THV remain most constrained at this level (Figure 1). Until recently, it was thought to be impossible to expand the neo-annulus.

\section{FRACTURING THE NEO-ANNULUS IN SURGICAL HEART VALVES}

The first reported case of intentional fracturing of SHV was reported by Nielsen-Kudsk and colleagues in $2015^{22}$; they fractured a Mitroflow SHV (Sorin Group, Arvada,
Colo) with a high-pressure balloon, so-called balloon valve fracture (BVF). The design features of the Mitroflow device, in which the stent frame made of polymer is attached by a joint and yields to the excessive force applied from within, allows room for expansion. Subsequent bench testing using different THV designs confirmed improvements in gradient and effective orifice area after BVF. ${ }^{23}$ Additional reports have demonstrated early feasibility of intentionally fracturing the sewing ring of SHV to improve the expansion of THV implanted in small SHVs. ${ }^{24,25}$ Few critical observations were made during bench testing. The size of the balloon required to fracture the SHV was at least equal to the label size. The balloon had to be a noncompliant, high-pressure balloon made of material such as Kevlar. Valve cracking occurred typically at high pressure, that is, 25 to $30 \mathrm{~atm}$. Valve cracking appeared to have not disrupted the fabric covering of the SHV. Among the SHV types implanted in the last 2 decades, the Mitroflow, Magna (Edwards Lifesciences, Irvine, Calif), Magna Ease (Edwards Lifesciences), Mosaic (Medtronic Inc, Minneapolis, Minn), and Biocor Epic (Abbott, St Paul, Minn) surgical valves could be successfully fractured using noncompliant high-pressure angioplasty balloons, whereas the Hancock II (Medtronic Inc) and Trifecta (Abbott) could not. ${ }^{24}$ The Trifecta SHV has a titanium frame without a joint and cannot be fractured. The construct of the sewing band in the Hancock II also resists fracturing.

Although in vitro testing has demonstrated that the sewing cuff was not disrupted despite fracture of the internal valve frame, the main concern in prescribing this approach routinely is the risk of annular injury and rupture. This complication has been anecdotally described but not reported. Chhatriwalla and colleagues ${ }^{26}$ have reported on 20 consecutive clinical cases of BVF performed in 9 centers across the United States as part of an ongoing study. A variety of SHVs were treated, including the Perimount (Carpentier Edwards, Irvine, Calif), Magna, Carpentier Edwards porcine, Mosaic, Mitroflow, Epic (Abbott), and Epic Supra (Abbott). Label size ranged from 19 to $25 \mathrm{~mm}$, but only SHVs with a true internal diameter less than $21 \mathrm{~mm}$ were treated. Types of THV used (ie, SAPIEN XT, SAPIEN 3 [Edwards Lifesciences], or CoreValve Evolut [Medtronic Inc]) and timing of the balloon fracture (ie,

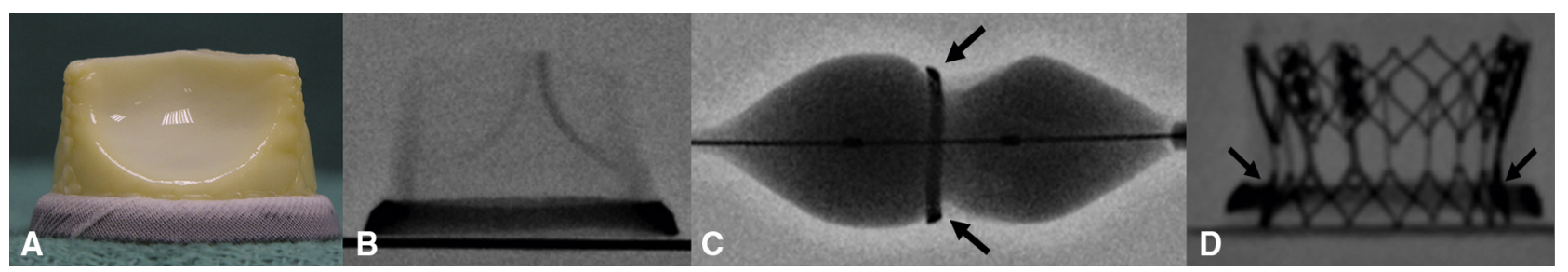

FIGURE 1. Concept of neo-annulus. A, Image of Mitroflow valve (Sorin Group, Arvada, Colo). B, Fluoroscopic appearance of the Mitroflow valve sewing ring is visible. C, Balloon inflation within the Mitroflow valve demonstrates zone of restrain (black arrows). D, SAPIEN XT (Edwards Lifesciences, Irvine, Calif) implantation within Mitroflow demonstrates uneven expansion of the SAPIEN XT valve with a "waist" at the level of the sewing ring (black arrows). 
before or after implantation of the THV) were left to the discretion of the operator. Although the burst pressure was significant highly than what we would encounter during valve implantation with balloon-expandable valves (ie, from 8 to $24 \mathrm{~atm}$ ), no intraprocedural complications were reported. Improved hemodynamics and frame expansion of THV implanted in fractured SHVs were observed. ${ }^{27}$ This novel technique may potentially improve PPM and hemodynamic outcomes in patients with small surgical bioprostheses undergoing VIV TAVR.

There remain many unknowns of balloon fracturing of the stent frame of SHV in the VIV procedure. Sizing the appropriate balloon for the particular surgical valve has not been established. ${ }^{26}$ A larger balloon may fracture the SHV at a lower inflation pressure, whereas a smaller balloon may generate lower radial force against the basal ring of the SHV. Using a larger balloon may risk injuring adjacent aortic root structures, such as the sinotubular junction or left ventricular outflow tract. Improved expansion of the THV may further displace the thickened SHV leaflets outward, increasing the risk of coronary obstruction, because the SHV leaflet-to-coronary distance will be reduced as the result of THV expansion in an unpredictable manner. The BASILICA technique may mitigate against this potential risk but is currently complex and should be performed only at experienced centers. The timing of balloon fracturing is also unclear. Fracturing before VIV implantation may cause leaflet damage and embolization, or acute hemodynamic decompensation, especially in patients without significant prosthetic aortic regurgitation. On the other hand, balloon fracturing after VIV implantation may damage the leaflets of the THV, given that larger-sized noncompliant balloons will be used under higher bursting pressure than what would be used typically postdilatation. Acute
THV failure as a result of surgical valve fracturing has been anecdotally described and may lead to potentially catastrophic complications. Also, it remains unclear whether after BVF a THV can become fully expanded and whether a more expanded THV may reduce the risk of leaflet thrombosis. Furthermore, given that BVF was intended to address the concern of residual elevated THV gradient after VIV TAVR, especially in small SHVs, we do not believe BVF would be necessary if the post-VIV TAVR mean gradient is less than $20 \mathrm{~mm} \mathrm{Hg}$ or mirrors expected SHV gradients. Using both echocardiography and invasive hemodynamics to assess THV gradient at the time of the procedure would be helpful to determine whether BVF would be necessary. Judicious balloon use after dilatation with a balloon size equivalent of $1 \mathrm{~mm}$ greater than the internal diameter of SHV may be sufficient to reduce the THV gradient. This more conservative strategy may be especially relevant in SHV, in which the primary dysfunction is prosthetic aortic stenosis and the SHV leaflets would be stiff and calcified, and there would be a risk of coronary obstruction if BVF were to be performed. Finally, significant PPM and the "Russian doll" effect may remain in small SHVs despite BVF. Although the THV effective orifice area and gradient may improve after BVF, preexisting severe PPM with the small SHV may remain, and the potential benefit of BVF and VIV TAVR may be attenuated. Reoperative SAVR, with possible aortic root enlargement in patients with small annuli who are not high risk for surgery, may be a reasonable alternative, given the outcomes in reoperative SAVR remained acceptable and were found to be similar to those of VIV TAVR. ${ }^{28-30}$ Thus, we believe that further bench testing to understand the implication of this novel therapy is a must and should be used only in select groups of high- or extreme-risk patients.

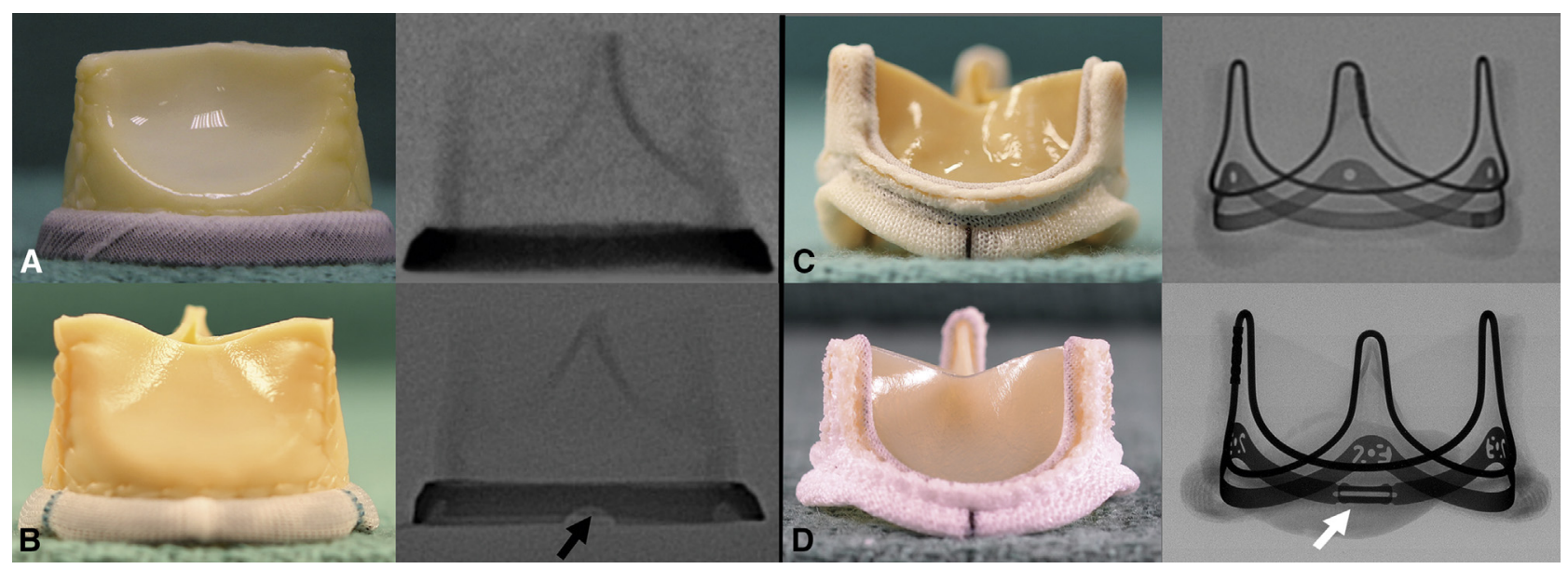

FIGURE 2. TAVR-friendly SHV designs. A, Mitroflow SHV image and fluoroscopic appearance. B, Crown SHV with cut-outs in the sewing ring at the level of stent posts (black arrows). C, Magna Ease (Edwards Lifesciences): image and fluoroscopic appearance. D, Inspiris SHV (Edwards Lifesciences) with label size markers and expansion mechanism in the basal band (white arrow). 


\section{CONCLUSIONS}

Going a step further, it is obvious that for VIV therapy to be a viable option in patients with a degenerated SHV, the SHV design must be modified to minimize or eliminate the aforementioned limitations and complications. We have already witnessed this in the form of the Crown valve (next-generation Mitroflow) manufactured by LivaNova (London, England) with sewing ring indents to help identify position of the stent posts under fluoroscopy (Figure 2, A and $B$ ), the Inspiris valve manufactured by Edwards Lifesciences with label size markers and expansion mechanism in its basal ring (Figure 2, $C$ and $D$ ), and the Avalus valve manufactured by Medtronic Inc, with a design to minimize the risk of coronary obstruction. Such design changes in SHV should facilitate future VIV procedures, but until then, ingenious methods such as SHV fracturing may be the only way to optimize the VIV procedure in select patients.

\section{Conflict of Interest Statement}

V.B. is a consultant for Edwards Lifesciences, Medtronic Inc, and 4Tech. G.H.L.T. is a physician proctor for Edwards Lifesciences and Medtronic.

\section{References}

1. Chiang YP, Chikwe J, Moskowitz AJ, Itagaki S, Adams DH, Egorova NN. Survival and long-term outcomes following bioprosthetic vs mechanical aortic valve replacement in patients aged 50 to 69 years. JAMA. 2014;312:1323-9.

2. Webb JG, Mack MJ, White JM, Dvir D, Blanke P, Herrmann HC, et al. Transcatheter aortic valve implantation within degenerated aortic surgical bioprostheses: PARTNER 2 valve-in-valve registry. J Am Coll Cardiol. 2017;69:2253-62.

3. Deeb GM, Chetcuti SJ, Reardon MJ, Patel HJ, Grossman PM, Schreiber T, et al. 1-year results in patients under going transcatheter aortic valve replacement with failed surgical bioprostheses. J Am Coll Cardiol Intv. 2017;10:1034-44.

4. Dvir D, Webb JG, Bleiziffer S, Pasic M, Waksman R, Kodali S, et al. Transcatheter aortic valve implantation in failed bioprosthetic surgical valves. JAMA. 2014;312:162-70.

5. Grover FL, Vemulapalli S, Carroll JD, Edwards FH, Mack MJ, Thourani VH, et al. 2016 annual report of the Society of Thoracic Surgeons/American College of Cardiology transcatheter valve therapy registry. J Am Coll Cardiol. 2017;69: 1215-30.

6. Yoon SH, Whisenant BK, Bleiziffer S, Delgado V, Schofer N, Eschenbach L, et al. Transcatheter mitral valve replacement for degenerated bioprosthetic valves and failed annuloplasty rings. J Am Coll Cardiol. 2017;70:1121-31.

7. McElhinney DB, Cabalka AK, Aboulhosn JA, Eicken A, Boudjemline Y, Schubert S, et al. Transcatheter tricuspid valve-in-valve implantation for the treatment of dysfunctional surgical bioprosthetic valves: an international, multicenter registry study. Circulation. 2016;133:1582-93.

8. Cabalka AK, Hellenbrand WE, Eicken A, Kreutzer J, Gray RG, Bergersen L, et al. Relationships among conduit type, pre-stenting, and outcomes in patients undergoing transcatheter pulmonary valve replacement in the prospective North American and European melody valve trials. JACC Cardiovasc Interv. 2017;10: 1746-59.

9. Wilson WM, Benson LN, Osten MD, Shah A, Horlick EM. Transcatheter pulmonary valve replacement with the Edwards Sapien system: the Toronto experience. JACC Cardiovasc Interv. 2015;8:1819-27.

10. Harken DE, Taylor WJ, Lefemine AA, Lunzer S, Low HB, Cohen ML, Jacobey JA. Aortic valve replacement with a caged ball valve. Am J Cardiol. 1962;9:292-9.

11. Dvir D, Leipsic J, Blanke P, Ribeiro HB, Kornowski R, Pichard A, et al. Coronary obstruction in transcatheter aortic valve-in-valve implantation: preprocedural evaluation, device selection, protection, and treatment. Circ Cardiovasc Interv. 2015;8:e002079.

12. Blanke P, Soon J, Dvir D, Park JK, Naoum C, Kueh SH, et al. Computed tomography assessment for transcatheter aortic valve in valve implantation: the Vancouver approach to predict anatomical risk for coronary obstruction and other considerations. J Cardiovasc Comput Tomogr. 2016;10:491-9.

13. Khan JM, Dvir D, Greenbaum AB, Babaliaros VC, Rogers T, Aldea G, et al Transcatheter laceration of aortic leaflets to prevent coronary obstruction during transcatheter aortic valve replacement: concept to first-in-human. JACC Cardiovasc Interv. 2018;11:677-89.

14. Hatosum H, Moore BL, Maureira P, Dollery J, Crestanello JA, Dasi LP. Aortic sinus flow stasis likely in valve-in-valve transcatheter aortic valve implantation. J Thorac Cardiovasc Surg. 2017;154:32-43.

15. Jose J, Sulimov DS, El-Mawardy M, Sato T, Allali A, Holy EW, et al. Clinical bioprosthetic heart valve thrombosis after transcatheter aortic valve replacement: incidence, characteristics, and treatment outcomes. JACC Cardiovasc Interv. 2017;10:686-97.

16. Azadani AN, Reardon M, Simonato M, Aldea G, Nickenig G, Kornowski R, et al. Effect of transcatheter aortic valve size and position on valve-in-valve hemodynamics: an in vitro study. J Thorac Cardiovasc Surg. 2017;153:1303-15.

17. Ainasser S, Cheema AN, Simonato M, Barbanti M, Edwards J, Kornowski R, et al Matched comparison of self-expanding transcatheter heart valves for the treatmen of failed aortic surgical bioprosthesis: insights from the valve-in-valve international data registry (VIVID). Circ Cardiovasc Interv. 2017;10:e004392.

18. Seiffert M, Conradi L, Baldus S, Knap M, Schirmer J, Franzen O, et al. Impact of patient-prosthesis mismatch after transcatheter aortic valve-in-valve implantation in degenerated bioprostheses. J Thorac Cardiovasc Surg. 2012;143:617-24.

19. Simonato M, Webb J, Kornowski R, Vahanian A, Frerker C, Nissen H, et al. Transcatheter replacement of failed bioprosthetic valves: large multicenter assessment of the effect of implantation depth on hemodynamics after aortic valve-in-valve. Circ Cardiovasc Interv. 2016;9:e003651.

20. Bapat VN, Attia R, Thomas M. Effect of valve design on the stent internal diameter of a bioprosthetic valve: a concept of true internal diameter and its implications for the valve-in-valve procedure. JACC Cardiovasc Interv. 2014;7:115-27.

21. Bapat V, Adams B, Attia R, Noorani A, Thomas M. Neo-annulus: a reference plane in a surgical heart valve to facilitate a valve-in-valve procedure. Catheter Cardiovasc Interv. 2015;85:685-91.

22. Nielsen-Kudsk JE, Christiansen EH, Terkelsen CJ, Norgaard BL, Jensen KT, Krusell LR, et al. Fracturing the ring of small Mitroflow bioprostheses by high-pressure balloon predilatation in transcatheter aortic valve-in-valve implantation. Circ Cardiovasc Interv. 2015;8:e002667.

23. Sathananthan J, Sellers S, Barlow AM, Stanova V, Fraser R, Toggweiler S, et al. Valve-in-valve transcatheter aortic valve replacement and bioprosthetic valve fracture comparing different transcatheter heart valve designs: an ex vivo bench study. J Am Coll Cardiol Intv. 2019;12:65-75.

24. Allen KB, Chhatriwalla AK, Cohen DJ, Saxon JT, Aggarwal S, Hart A, et al. Bioprosthetic valve fracture to facilitate transcatheter valve-in-valve implantation. Ann Thorac Surg. 2017;104:1501-8.

25. Nielsen-Kudsk JE, Andersen A, Therkelsen CJ, Christensen EH, Jensen KT, Krusell LR, et al. High-pressure balloon fracturing of small dysfunctional Mitroflow bioprostheses facilitates transcatheter aortic valve-in-valve implantation. Eurointervention. 2017;13:e1020-5.

26. Chhatriwalla AK, Allen KB, Saxon JT, Cohen DJ, Aggarwal S, Hart AJ, et al. Bioprosthetic valve fracture improves the hemodynamic results of valve-in valve transcatheter aortic valve replacement. Circ Cardiovasc Interv. 2017;10 e005216.

27. McElhinney DB. When device failure translates to therapeutic efficacy: intentional fracture of bioprosthetic valve rings as an adjunctive technique in transcatheter valve-in-valve replacement. Circ Cardiovasc Interv. 2017;10:e005662.

28. Kaneko T, Vassileva CM, Englum B, Kim S, Yammine M, Brennan M, et al. Contemporary outcomes of repeat aortic valve replacement: a bench for transcatheter valve-in-valve procedures. Ann Thorac Surg. 2015;100: 1298-304.

29. Stulak JM, Tchantchaleishvili V, Daly RC, Eleid MF, Greason KL, Dearani JA, et al. Conventional redo biological valve replacement over 20 years: surgical benchmarks should guide patient selection for transcatheter valve-in-valve therapy. J Thorac Cardiovasc Surg. 2018;156:1380-90.

30. Tuzcu EM, Kapadia SR, Vemulapalli S, Carroll JD, Holmes DR, Mack MJ, et al Transcatheter aortic valve replacement of failed surgically implanted bioprostheses: the STS/ACC registry. J Am Coll Cardiol. 2018;72:370-82. 